\title{
Persistence and adverse events of biological treatment in adult patients with juvenile idiopathic arthritis: results from BIOBADASER
}

Juan José Bethencourt Baute ${ }^{1}$, Carlos Sanchez-Piedra², Dolores Ruiz-Montesinos ${ }^{3}$, Marta Medrano San Ildefonso ${ }^{4}$, Carlos Rodriguez-Lozano ${ }^{5}$, Eva Perez-Pampin ${ }^{6}$, Ana Ortiz ${ }^{7}$, Sara Manrique ${ }^{8}$, Rosa Roselló ${ }^{2}$, Victoria Hernandez ${ }^{10}$, Cristina Campos ${ }^{11}$, Agustí Sellas ${ }^{12}$, Walter Alberto Sifuentes-Giraldo ${ }^{13}$, Javier García-González ${ }^{14}$, Fernando Sanchez-Alonso ${ }^{2}$, Federico Díaz-González ${ }^{15}$, Juan Jesús Gómez-Reino ${ }^{6}$, Sagrario Bustabad Reyes ${ }^{15^{*}}$ and on behalf of the BIOBADASER study group

\section{Abstract}

Background: Biologic therapy has changed the prognosis of patients with juvenile idiopathic arthritis (JIA). The aim of this study was to examine the pattern of use, drug survival, and adverse events of biologics in patients with JIA during the period from diagnosis to adulthood.

Methods: All patients included in BIOBADASER (Spanish Registry for Adverse Events of Biological Therapy in Rheumatic Diseases), a multicenter prospective registry, diagnosed with JIA between 2000 and 2015 were analyzed. Proportions, means, and SDs were used to describe the population. Incidence rates and 95\% Cls were calculated to assess adverse events. Kaplan-Meier analysis was used to compare the drug survival rates.

Results: A total of 469 patients (46.1\% women) were included. Their mean age at diagnosis was $9.4 \pm 5.3$ years. Their mean age at biologic treatment initiation was $23.9 \pm 13.9$ years. The pattern of use of biologics during their pediatric years showed a linear increase from 24\% in 2000 to $65 \%$ in 2014. Biologic withdrawal for disease remission was higher in patients who initiated use biologics prior to 16 years of age than in those who were older ( $25.7 \%$ vs $7.9 \%, p<0.0001)$. Serious adverse events had a total incidence rate of $41.4(35.2-48.7)$ of 1000 patient-years. Patients younger than 16 years old showed significantly increased infections $(p<0.001)$.

Conclusions: Survival and suspension by remission of biologics were higher when these compounds were initiated in patients with JIA who had not yet reached 16 years of age. The incidence rate of serious adverse events in pediatric vs adult patients with JIA treated with biologics was similar; however, a significant increase of infection was observed in patients under 16 years old.

Keywords: Juvenile idiopathic arthritis, Biologic treatment, Safety therapy, Clinical practice

\footnotetext{
* Correspondence: sagrario.bustabad@gmail.com

${ }^{15}$ Servicio de Reumatología, Hospital Universitario de Canarias, c/Ofra s/n

38320, La Laguna, Santa Cruz de Tenerife, Spain

Full list of author information is available at the end of the article
}

(c) The Author(s). 2018 Open Access This article is distributed under the terms of the Creative Commons Attribution 4.0 International License (http://creativecommons.org/licenses/by/4.0/), which permits unrestricted use, distribution, and reproduction in any medium, provided you give appropriate credit to the original author(s) and the source, provide a link to the Creative Commons license, and indicate if changes were made. The Creative Commons Public Domain Dedication waiver (http://creativecommons.org/publicdomain/zero/1.0/) applies to the data made available in this article, unless otherwise stated. 


\section{Background}

Juvenile idiopathic arthritis (JIA) comprises a group of diseases of unknown etiology that have in common arthritis in at least one joint persisting for at least 6 weeks in patients younger than 16 years of age [1]. JIA is the most frequent chronic rheumatic disease in childhood [2-4] and is classified into seven categories: systemic, persistent or extended oligoarthritis, rheumatoid Factor (RF) positive polyarthritis, RF-negative polyarthritis, enthesitis-related arthritis, psoriatic arthritis, and undifferentiated arthritis [1]. When uncontrolled, JIA leads to severe joint damage and impairment in skeletal maturation [5-7]. Fortunately, during the last decade, the arrival of biologics has dramatically changed the prognoses for these patients $[8,9]$. A number of well-designed clinical trials, as well as cohort studies, have demonstrated that biologics are an effective option for patients with JIA who do not respond to or who cannot tolerate treatment with synthetic disease-modifying antirheumatic drugs (DMARDs) [10-12]. Some studies have shown that the sooner treatment is begun for JIA and the more aggressive it is, the better the outcomes obtained [13-16]. The ReACCh-Out cohort studied remission in patients with JIA in Canada and concluded that the probability of attaining remission with contemporary treatments within 5 years of diagnosis averaged about $50 \%$, except for children with polyarthritis [17].

JIA is not confined to childhood, and $41 \%$ of patients require medication in their thirties, with some $28 \%$ maintaining high disease activity [18]. The transition period from pediatric- to adult-focused health care for adolescents with chronic conditions is attracting growing attention [19]. A recent study assessing the importance of transition to adult rheumatologic care in young people with JIA concluded that the maintenance of JIA diagnosis and DMARD therapy depended on the use of specialized care services [20]. Nowadays, young people with rheumatic diseases have a greater rate of survival, although high morbidity persists that could be avoided, in part, with multidisciplinary management [21]. Recently, several professional groups and international agencies have attempted to create consensus recommendations and guidelines trying to improve this situation [22,23]. Data from the British Society for Rheumatology Biologics Register shows that tumor necrosis factor inhibitor (TNFi) therapies are an effective treatment option for adults with JIA, with a safety profile similar to that seen in rheumatoid arthritis (RA) [24]. However, because adults with JIA comprise a heterogeneous group of patients whose clinical evolution, need for, and response to treatments are not well studied, follow-up and monitoring of these patients are required [25]. The aim of the present study was to evaluate the pattern of use, the survival, and the safety of biologic agents in patients with JIA during the period from diagnosis to adulthood who are included in the BIOBADASER registry.

\section{Methods}

Study design

BIOBADASER (Spanish Registry for Adverse Events of Biological Therapy in Rheumatic Diseases) is a multicenter prospective observational study monitored annually, the main objective of which is long-term safety assessments of patients who undergoing biologic therapies [26, 27]. Established in February 2000, BIOBADASER is based on clinical practice. The quality of the database is ensured by a clear definition of its aim, an optimized number of variables, and an easy method of data collection that allows for consistency checks. Incompleteness and agreement of data with patient charts are assessed by online monitoring of the entire included population and by on-site annual audits of $10 \%$ of the patients registered. All detected errors and inconsistencies are corrected on the basis of results of said monitoring. The BIOBADASER registry is supported by the Spanish Medicines Agency, and the clinical studies were approved by the ethics committee of Hospital Clinic Barcelona. All patients included in the BIOBADASER registry, or their legal representatives, signed a written informed consent prior to inclusion.

\section{Population}

For this analysis, we selected all adult patients included in the database diagnosed with JIA. Owing to the initial design of the registry (BIOBADASER was not initially designed as a specific registry for JIA), patients with JIA were classified into systemic/oligoarthritis/polyarticular JIA, JIA related to enthesitis, or psoriatic JIA. Patients were enrolled in the registry when biologic treatment was initiated, and they were followed prospectively and evaluated if an adverse event (AE) occurred or if a change in the biologic therapy was decided either owing to an $\mathrm{AE}$ or because of inefficacy. The analysis of this study includes data from 2000 to December 2015, and only those patients still under active follow-up at the end of the study period were included.

\section{Variables}

The following data were collected: (1) patient data, including gender, date of birth, diagnosis, date of diagnosis, and comorbidities; (2) data on treatment, including types of biologics and dates of initiation and discontinuation, reason for discontinuation, concomitant antirheumatic treatment and tuberculosis (TB) prophylaxis; and (3) data on AEs, including date of occurrence, type and classification of $\mathrm{AE}$ according to the Medical Dictionary for Regulatory Activities [MedDRA]) v13 [28], severity, and outcome.

\section{Statistical analysis}

The patients included were described using descriptive statistics indicated by the type and distribution of variables. Proportions, means, and SDs or IQRs were used 
to describe our population and the use of treatments. The incidence rate (IR) per 1000 patient-years with 95\% CI was estimated by group. Results were expressed as IR with the $95 \%$ CI. Survival rates were defined as end of treatment for any reason. IR comparisons between age groups were obtained by Poisson regression. Log-rank tests were used to assess the equality of survivor functions across age groups, monotherapy vs combined therapy, and treatment groups. All analyses were performed using Stata version 13.1 software (StataCorp, College Station, TX, USA).

\section{Results}

A total of 469 patients from the BIOBADASER registry, $46.1 \%$ of them women $(n=216)$, were classified as systemic/oligoarthritis/polyarticular JIA (70.5\%), JIA related to enthesitis (25\%), and psoriatic JIA (4.5\%). The mean age was 34.5 years $(\mathrm{SD}=15.3)$. The mean age at diagnosis was 9.4 years $(\mathrm{SD}=5.3)$, and the mean evolution years was 24.1 $(\mathrm{SD}=14.1)$. Uveitis was recorded in $12.6 \%$ of patients $(50 \%$ of them antinuclear antibody [ANA]-positive). Overall, the ANA test result was positive in $30.2 \%$ of patients with systemic/oligoarthritis/polyarticular JIA, $14.3 \%$ of patients with psoriatic JIA, and $6.8 \%$ of patients with enthesitis. HLA-B27 was determined in $42.9 \%$ of patients, with $22 \%$ testing positive (59.8\% in enthesitis-related arthritis, $23.8 \%$ in psoriatic arthritis, and $8.5 \%$ in systemic/oligoarthritis/ polyarticular JIA). The mean age at the beginning of biologic treatment was 23.9 years $(S D=13.9)$, and the mean number of years that patients were treated with these compounds was $9.6(\mathrm{SD}=3.8)$. Table 1 shows the baseline characteristics of patients included in this analysis.

Table 2 shows the biologics and concomitant treatments. The most frequently used biologics as first-line treatments were etanercept (43.5\%), infliximab (30.5\%), and adalimumab (19\%). Almost half of the patients included in the registry (42.4\%) were receiving monotherapy with biologics, and corticoids were used in $32.3 \%$ of patients with JIA. With respect to the pattern of use, Fig. 1 shows the annual percentage of patients diagnosed of JIA from 2000 to 2015 whose treatment with biologics began at age 16 years or younger $(n=137)$. In $2000,25 \%$ of patients received the first biologic at a pediatric age, with this percentage increasing linearly until reaching $65 \%$ in 2015. The mean age of patients who started biologic treatment before 16 years of age was 8.06 years $(\mathrm{SD}=4.3)$.

Table 3 shows the type of biologic used in the initial treatment of patients younger vs older than 16 years old. Etanercept was the most frequently prescribed drug as a first-line treatment in patients under 16 years old (59.1\%), whereas infliximab was the most often biologic used in those aged 16 years or older (40.4\%). Maintaining this division, the reasons for suspension in both groups of ages were inefficiency (37.1\% and 37.4\%, respectively), followed by adverse effects $(28.6 \%$ and $28 \%$, respectively). The
Table 1 Baseline characteristics of patients included in the study

\begin{tabular}{|c|c|c|}
\hline Variable & Median (IQR) (Years) & No. (\%) \\
\hline Total number of patients & & 469 \\
\hline Sex, female & & $216(46.1)$ \\
\hline $\mathrm{Age}^{\mathrm{a}}$ & $32.8[22.8-43.6]$ & \\
\hline Age at diagnosis & $10.3[4.4-14.3]$ & \\
\hline $\begin{array}{l}\text { Age at the beginning of biological } \\
\text { treatment, median }[\mathrm{IQR}]^{* *}\end{array}$ & $22.1[13.9-32.5]$ & \\
\hline Years of disease progression & $22.5[12.3-33.9]$ & \\
\hline Time in treatment with biologic & $9.7[6.8-12.6]$ & \\
\hline \multicolumn{3}{|l|}{ JIA categories: } \\
\hline $\begin{array}{l}\text { - Oligoarticular, polyarticular, } \\
\text { and systemic }\end{array}$ & & $331(70.5)$ \\
\hline - Enthesitis-related arthritis & & $117(25)$ \\
\hline - Psoriatic arthritis & & $21(4.5)$ \\
\hline Positive RF & & $32(6.8)$ \\
\hline ANA-positive & & $111(23.7)$ \\
\hline \multicolumn{3}{|l|}{ HLA-B27-positive: } \\
\hline - Positive & & $103(22)$ \\
\hline - Negative & & $98(20.9)$ \\
\hline - Not done & & $268(57.1)$ \\
\hline \multicolumn{3}{|l|}{ Uveitis: } \\
\hline - Without uveitis & & $410(87.4)$ \\
\hline - Uveitis, ANA-negative & & $30(6.4)$ \\
\hline - Uveitis, ANA-positive & & $29(6.2)$ \\
\hline
\end{tabular}

suspension rate due to disease remission was higher in patients who initiated biologic treatment before 16 years old $(25.7 \%)$ than in those who began it at 16 years old or later $(7.9 \% ; p<0.0001)$. A total of $266(56.7 \%)$ patients received only one biologic, and $7.5 \%$ were treated with five or more such compounds.

With respect to survival rates by age groups, retention of the first biologic was higher when it was started before 16 years of age ( $p=0.02)$ (Fig. 2a). However, when survival rates were analyzed in patients who had received biologics as monotherapy or in combination, no significant differences were observed in terms of biologic retention ( $p=0.52$ ) (Fig. 2b). Regarding the therapeutic target, a nonsignificant tendency toward a better retention of TNFi compounds with respect to non-TNFi was observed ( $p=0.06$ ) (Fig. 2c) when they were analyzed as a first- or second-line treatment.

Table 4 shows that the most frequent AEs were infections, gastrointestinal disorders, skin and subcutaneous tissue disorders, and site-of-administration reactions. Regarding serious AEs, no differences were observed if the biologic therapy was initiated before age 16 years vs 
Table 2 Biologics as first-line and subsequently, and concomitant therapy in patients with juvenile idiopathic arthritis

\begin{tabular}{llll}
\hline Drug & First-line & Second-line or later & Total \\
\hline Etanercept & $204(43.5)$ & $119(25.8)$ & $323(34.7)$ \\
Infliximab & $143(30.5)$ & $58(12.6)$ & $201(21.6)$ \\
Adalimumab & $89(19.0)$ & $108(23.4)$ & $197(21.2)$ \\
Anakinra & $8(1.7)$ & $15(3.3)$ & $23(2.5)$ \\
Rituximab & $0(0.0)$ & $72(15.6)$ & $72(7.7)$ \\
Abatacept & $5(1.1)$ & $28(6.1)$ & $33(3.6)$ \\
Tocilizumab & $16(3.4)$ & $40(8.7)$ & $56(6.0)$ \\
Golimumab & $2(0.4)$ & $13(2.8)$ & $15(1.6)$ \\
Certolizumab & $2(0.4)$ & $5(1.1)$ & $7(0.8)$ \\
Canakinumab & $0(0.0)$ & $2(0.4)$ & $2(0.2)$ \\
Ustekinumab & $0(0.0)$ & $1(0.2)$ & $1(0.1)$ \\
Use of concomitant drugs & & & $394(42.4)$ \\
- Monotherapy & $177(37.7)$ & $217(47.1)$ & $409(44.0)$ \\
- Methotrexate & $225(48.0)$ & $184(39.9)$ & $300(32.3)$ \\
- Glucocorticoids & $155(33.1)$ & $145(31.5)$ & $55(5.9)$ \\
- Leflunomide & $29(6.2)$ & $26(5.7)$ & $39(4.2)$ \\
- Sulfasalazine & $26(5.5)$ & $13(2.8)$ & $1(0.1)$ \\
- Gold salts & $1(0.2)$ & - & $8(0.9)$ \\
- Azathioprine & $3(0.6)$ & $5(1.1)$ & $5(1.0)$ \\
- Hydroxychloroquine & $4(0.9)$ & 5 &
\end{tabular}

Data are expressed as number of patients (\%)

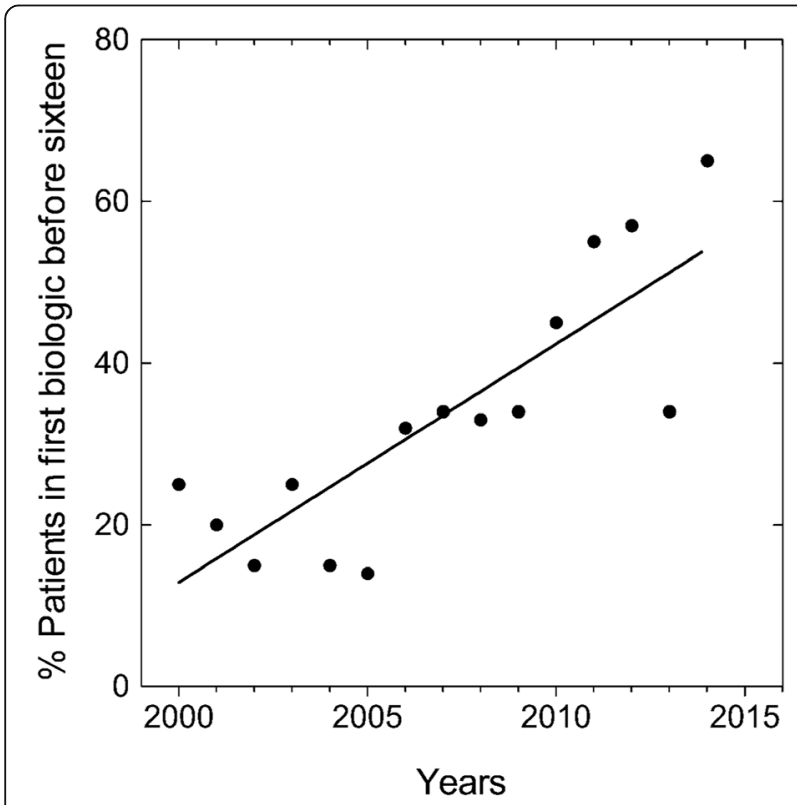

Fig. 1 Dot plot showing the variations in the percentage of patients with juvenile idiopathic arthritis included in BIOBADASER annually who received their first biologic before age 16 since years 2000 to 2015
Table 3 Characteristics of patients by age at the beginning of biologic treatment according to biologic compound, number of biologic drugs, and reasons for suspension

\begin{tabular}{|c|c|c|c|}
\hline & $<16$ Years & $\geq 16$ Years & $p$ Value \\
\hline Number of patients & $137(29.2)$ & $332(70.8)$ & \\
\hline $\begin{array}{l}\text { Age at the beginning of } \\
\text { biological treatment }\end{array}$ & $9.0[4.2]$ & $30.2[11.4]$ & $<0.001$ \\
\hline Years of disease progression & $2.7[3.1]$ & $19.5[2.1]$ & $<0.001$ \\
\hline \multicolumn{4}{|l|}{ Biologic compound } \\
\hline Etanercept & $81(59.1)$ & $123(37.1)$ & $<0.001$ \\
\hline Adalimumab & $31(21.6)$ & $58(17.5)$ & \\
\hline Infliximab & $9(6.6)$ & $134(40.4)$ & \\
\hline Tocilizumab & $8(5.8)$ & $8(2.4)$ & \\
\hline Abatacept & - & $5(1.5)$ & \\
\hline Anakinra & $6(4.4)$ & $2(0.6)$ & \\
\hline Certolizumab & $2(1.5)$ & - & \\
\hline Golimumab & - & $2(0.6)$ & \\
\hline \multicolumn{4}{|l|}{ Reason for suspension } \\
\hline Inefficacy & $26(37.1)$ & $80(37.4)$ & $<0.001$ \\
\hline Remission & $18(25.7)$ & $17(7.9)$ & \\
\hline Adverse event & $20(28.6)$ & $60(28.0)$ & \\
\hline Loss of tracking & $4(5.7)$ & $20(9.4)$ & \\
\hline Pregnancy or gestational desire & - & $13(6.1)$ & \\
\hline Other reasons & $2(2.9)$ & $22(10.3)$ & \\
\hline Unknown & - & $2(0.9)$ & \\
\hline \multicolumn{4}{|l|}{ Number of biologic drugs } \\
\hline 1 drug & $83(60.6)$ & $183(55.1)$ & 0.244 \\
\hline$>1$ drug & $54(39.4)$ & $149(44.9)$ & \\
\hline 2 & 27 (19.7) & $67(20.2)$ & \\
\hline 3 & $13(9.5)$ & 38 (11.5) & \\
\hline 4 & $11(8.0)$ & $12(3.6)$ & \\
\hline 5 or more & $3(2.2)$ & $32(9.6)$ & \\
\hline
\end{tabular}

Data are expressed as mean [SD] or as number of patients (\%). Chi-squared tests were used to compare distributions for categorical variables, and Student's $t$ tests were used for numerical variables

later. Conversely, the analysis of infections showed a significant increase in the IR in patients under 16 years of age: $253.2(221.4-289.6)$ vs $136.0(122.8-150.6) \quad(p<$ 0.001 ). A total of $37.2 \%$ of infections occurred during the first year of treatment (only $4.0 \%$ in the first month). Additional file 1: Table S1 shows the frequency of infections classified by type in patients younger or older than 16 years old. Only one fatal event (mycoplasma pneumonia in a patient treated with anakinra) was recorded. The IRs of total AEs in the three categories in which BIOBADASER classified patients with JIA were as follows: 424.9 (399.8451.7) for systemic/oligoarthritis/polyarticular JIA, 262.8 (232-297.9) in cases of enthesitis, and 252.9 (188.8-338.8) for psoriatic JIA $(p<0.001)$. Regarding serious AEs, the 


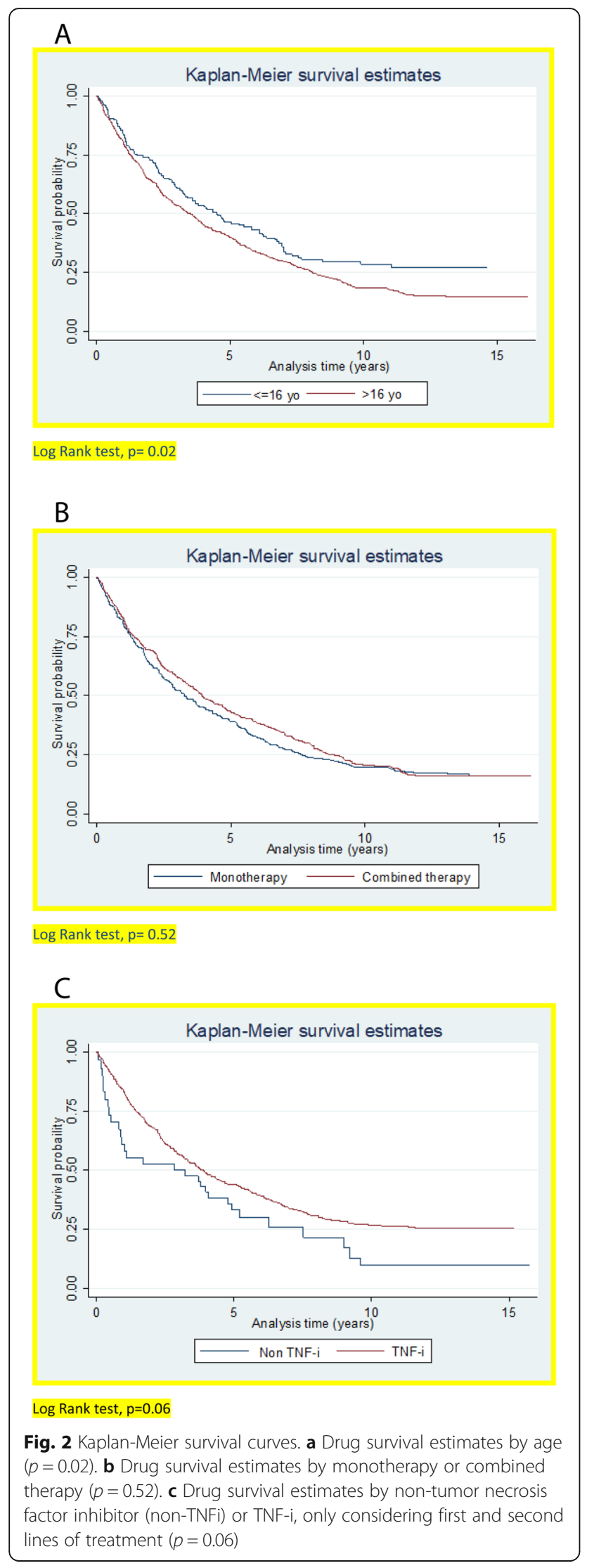

IRs were 44.1 (36.5-53.3), 36 (25.7-50.4), and 33.7 (15.2$75.1)$, respectively $(p=0.36)$. When patients with JIA were classified on the basis of biologic therapy with TNFi or non-TNFi, the IRs for total AEs were 345.0 (325.1-366.0) and 617 (541.7-702.8), respectively $(p=0.009)$. Regarding serious AEs, the IRs were $78.8(54.8-113.4)$ and 37.1 (30.9-44.4), respectively $(p=0.924)$.

With respect to opportunistic infections, three cases of pulmonary TB and one case of disseminated TB were recorded; these patients had received chemoprophylaxis with isoniazid, except in one case owing to a negative Mantoux test result.

\section{Discussion}

The most important findings of this work can be summarized as follows:

1. The use of biologics for the management of JIA during the pediatric years has consistently increased during the last 15 years.

2. In patients with JIA treated with biologics before 16 years of age, both the survival and drug withdrawal due to disease remission are higher than when these compounds are started during adulthood.

3. The safety of biologics in JIA is similar when used before or after 16 years of age in cases of serious AEs; however, in patients younger than 16 years old, infections are more frequent.

During the last 15 years, the advent of biologic drugs has changed the prognosis of and therapeutic approach to many rheumatic diseases, including JIA. As in adults, early initiation of biologic therapy in pediatric patients with JIA is important when control of the disease with conventional DMARDs is not achievable [29-31]. Patients with active JIA refractory to DMARDs and steroids are currently treated with TNFi or interleukin-6 antagonists or T-cell activation inhibitors in order to maintain inactive disease and the remission of JIA. Biologic drugs are typically well tolerated by children, and that-combined with early and aggressive therapy-yields optimal outcomes [9]. In this regard, in our present study, the pattern of biologic use showed that the annual percentage of patients with JIA who began treatment with these compounds before reaching 16 years of age increased almost threefold from 2000 to 2015. The biologics used in our registry of patients were, in order of frequency: etanercept, infliximab, and adalimumab. Infliximab was the second most used biologic in our series, with $30.5 \%$ of patients receiving this compound as the first biologic drug. Similarly, previous studies have reported the use of infliximab as a first biologic in patients with JIA ranged between $20.6 \%$ and $32 \%[24,32]$. When differentiating whether the treatment was started before or after 16 years old, it was found than $93 \%$ of patients $(n=134)$ initiated infliximab in adulthood. The reason for the significant use of infliximab, a TNFi 
Table 4 Incidence of adverse events recorded in patients with juvenile idiopathic arthritis

\begin{tabular}{|c|c|c|c|c|}
\hline & \multicolumn{2}{|l|}{ By age } & \multirow{2}{*}{$\begin{array}{l}p \\
\text { Value }\end{array}$} & \multirow[t]{2}{*}{ Total } \\
\hline & $<16$ years & $\geq 16$ years & & \\
\hline Total adverse events & $457.6(414.1-505.7)$ & $346.9(325.4-369.8)$ & $<0.001$ & $373.2(353.6-393.8)$ \\
\hline Serious adverse events & $35.7(24.9-51.0)$ & $43.2(36.1-51.8)$ & 0.347 & $41.4(35.2-48.7)$ \\
\hline Fatal adverse events & $1.2(0.2-8.4)$ & - & 0.999 & $0.3(0.0-2.0)$ \\
\hline \multicolumn{5}{|l|}{ By system/organ class } \\
\hline Infections and infestations & $253.2(221.4-289.6)$ & $136.0(122.8-150.6)$ & $<0.001$ & $163.8(151-177.6)$ \\
\hline Gastrointestinal disorders & $30.9(21.0-45.4)$ & $18.1(13.7-24.0)$ & 0.028 & $21.1(16.9-26.5)$ \\
\hline Skin and subcutaneous tissue disorders & $17.8(10.7-29.6)$ & $21.1(16.2-27.3)$ & 0.797 & $20.3(16.1-25.6)$ \\
\hline General disorders and administration site conditions & $21.4(13.5-34.0)$ & $20.0(15.3-26.0)$ & 0.566 & $20.3(16.1-25.6)$ \\
\hline Eye disorders & $23.8(15.3-36.8)$ & $13.3(9.6-18.4)$ & 0.037 & $15.8(12.1-20.5)$ \\
\hline Musculoskeletal and connective tissue disorders & $11.9(6.4-22.1)$ & $11.8(8.4-16.7)$ & 0.988 & $11.8(8.7-16)$ \\
\hline Surgical and medical procedures & $3.6(1.2-11.1)$ & $13.7(9.9-18.9)$ & 0.025 & $11.3(8.3-15.4)$ \\
\hline Nervous system disorders & $10.7(5.6-20.6)$ & $11.5(8.1-16.3)$ & 0.857 & $11.3(8.3-15.4)$ \\
\hline Blood and lymphatic system disorders & $10.7(5.6-20.6)$ & $8.9(5.9-13.2)$ & 0.631 & $9.3(6.6-13.1)$ \\
\hline Renal and urinary disorders & $3.6(1.2-11.1)$ & $11.1(7.7-15.9)$ & 0.061 & $9.3(6.6-13.1)$ \\
\hline Reproductive system and breast disorders & $4.8(1.8-12.7)$ & $9.6(6.5-14.1)$ & 0.190 & $8.5(5.9-12.1)$ \\
\hline Injury, poisoning, and procedural complications & $8.3(4.0-17.5)$ & $8.1(5.4-12.3)$ & 0.957 & $8.2(5.7-11.8)$ \\
\hline Respiratory, thoracic, and mediastinal disorders & $11.9(6.4-22.1)$ & $5.9(3.6-9.6)$ & 0.083 & $7.3(5-10.8)$ \\
\hline $\begin{array}{l}\text { Neoplasms: benign, malignant, and unspecified } \\
\text { (including cysts and polyps) }\end{array}$ & $3.6(1.2-11.1)$ & $5.9(3.6-9.6)$ & 0.422 & $5.4(3.4-8.4)$ \\
\hline Hepatobiliary disorders & $2.4(0.6-9.5)$ & $5.9(3.6-9.6)$ & 0.225 & $5.1(3.2-8.1)$ \\
\hline Metabolism and nutrition disorders & $1.2(0.2-8.4)$ & $5.9(3.6-9.6)$ & 0.120 & $4.8(3-7.7)$ \\
\hline Pregnancy, puerperium, and perinatal conditions & 0.0 & $5.5(3.3-9.2)$ & 0.997 & $4.2(2.5-7)$ \\
\hline Vascular disorders & $1.2(0.2-8.4)$ & $4.8(2.8-8.3)$ & 0.178 & $3.9(2.3-6.7)$ \\
\hline Psychiatric disorders & $5.9(2.5-14.3)$ & $3.3(1.7-6.4)$ & 0.298 & $3.9(2.3-6.7)$ \\
\hline Ear and labyrinth disorders & $2.4(0.6-9.5)$ & $3.0(1.5-5.9)$ & 0.783 & $2.8(1.5-5.2)$ \\
\hline Immune system disorders & $2.4(0.6-9.5)$ & $2.6(1.2-5.4)$ & 0.916 & $2.5(1.3-4.9)$ \\
\hline Cardiac disorders & $3.6(1.2-11.1)$ & $1.8(0.8-4.4)$ & 0.368 & $2.3(1.1-4.5)$ \\
\hline Endocrine disorders & $2.4(0.6-9.5)$ & $1.5(0.6-3.9)$ & 0.583 & $1.7(0.8-3.8)$ \\
\hline Congenital, familial, and genetic disorders & 0.0 & $1.8(0.8-4.4)$ & 0.403 & $1.4(0.6-3.4)$ \\
\hline
\end{tabular}

Data represent the incidence $(95 \% \mathrm{Cl}) \times 1000$ patients $/ \mathrm{yr}$

without indication in any category of JIA, in patients with JIA in adulthood may be due to different factors. These might be that infliximab and etanercept were the first TNFi available, and for a period of time they were the only biologic available, to treat DMARD-resistant inflammatory arthritis, as well as the tendency of many rheumatologists to reclassify adult JIA as RA [20], where infliximab is indicated.

The variable course of JIA and the passage from adolescence to adulthood constitutes an important challenge for the physician. According to a study conducted by the American College of Rheumatology, $45 \%$ of pediatric rheumatologists are reluctant to treat patients aged 18 years and older, and $28 \%$ of adult rheumatologists are treating patients younger than 17 years old [33]. Various studies have reported that one-third of patients with JIA continue to present clinical disease activity into adulthood [34-36]. In addition, most patients with JIA who start biologic therapy during childhood reach adulthood with little evidence to support the benefits of continuing these treatments [37-39] or even of their long-term safety. This scenario implies a greater complexity in monitoring the safety of those drugs than is currently acknowledged. Studies based on routine clinical practice, as presented in this work, allow the assessment of treatment effectiveness and long-term adverse reactions in daily practice.

In our study, those patients who started treatment with biologics before the age 16 years presented with a percentage of drug suspension, owing to disease remission, greater 
than that in those who initiated these compounds at a later age $(25.7 \%$ vs $7.9 \%$, respectively). Different European cohorts have reported that male sex and earlier initiation of biologic therapy increased the likelihood of halting treatment owing to the onset of clinical remission [40]. With respect to drug survival, we found a significantly better retention rate when biologics were started before age 16 than in adulthood. The gap between diagnosis and biologic treatment initiation in the group of patients younger than 16 was $2.7 \pm 3.1$ years. A previous report [41] found no differences in the retention rates of the biologic therapy based on the age of treatment initiation in patients with JIA. In this study, the median age of patients who started biologic therapy was $16.2 \pm 9.4$ years old, with a gap between initiation of biologic treatment and diagnosis of $7.5 \pm 4.9$ years. This difference in start time of biologic treatment with respect to diagnosis might explain, at least in part, the divergent results in retention rates vis-à-vis age of biologic initiation between the two studies. In terms of drug survival, we found no differences between the use of biologics in monotherapy vs in combination, and when differentiated by age, our results were similar to those previously reported [42].

The aim of this study was to collect long-term outcome data on children receiving biologic agents for JIA, not only to assess drug survival but also to explore the reasons why biologic therapies had been discontinued. In our group of patients, inefficacy was the main reason for biologic therapy discontinuation regardless of age at drug onset, followed by $\mathrm{AE}$ and remission. In this regard, other series have found dissimilar results. Verazza et al. [43], in a series of 1038 patients with JIA treated with etanercept, found that the main cause of treatment discontinuation was disease remission, followed by inefficacy and AEs. Nevertheless, in a cohort of 301 patients with JIA, the most common reasons for stopping biologic treatment were AEs, with infusion reactions being the most frequently reported [44]. In a comparative study of adult and juvenile populations with inflammatory arthritis [42], the same biologic therapy profile as in our study was observed (infliximab vs etanercept) in both adults and children. Inefficacy was the most frequent reason for discontinuation of biologic therapy in both groups, being neuropsychiatric, gastrointestinal, and ocular complications, but not infections, as the most frequents $\mathrm{AEs}$ in the juvenile population. Although it may seem interesting to compare incidences of AEs and survival curves head-to-head for biologic treatments in adult patients, this would involve analyzing two different populations with clearly differentiated baseline pathologies and characteristics.

Regarding the limitations of our study, BIOBADASER was not specifically designed for JIA, and the categorization of these patients differs from the most currently used classification [1]. Because correct classification in categories is important in terms of therapeutic indications and prognosis, the new 2016 version of BIOBADASER classifies patients with JIA as systemic, persistent, or extended oligoarthritis; RF-positive polyarthritis; RF-negative polyarthritis; enthesitis-related arthritis; psoriatic arthritis; and undifferentiated arthritis [1]. Another limitation of our study is that we did not compare drugs individually. Nevertheless, our results included a safety comparison between TNFi and other biologic therapies. With respect to strengths of BIOBADASER, this registry allows the possibility of studying safety information in biologic treatments in a large cohort of patients with JIA followed in routine clinical practice by rheumatologists during a relevant period. BIOBADASER adds to the limitations of randomized clinical trials, which typically include a relatively low number of subjects followed for a short period of time, which hampers the ability of such studies to detect rare events and/or long-term side effects [45].

\section{Conclusions}

In summary, thus far, there are few studies based on general clinical practice that focus on the safety of biologic treatments in patients with JIA. The prospective records of these adult patients with JIA treated with biologic therapy can contribute to improving knowledge about the behavior of this disease in adulthood. In our study, survival and suspension by remission of biologics were higher when these compounds were initiated in patients with JIA who had not yet reached 16 years of age. The IR of serious AE in child vs adult patients with JIA treated with biologics was similar.

\section{Additional file}

Additional file 1: Table S1. Frequency of infections, classified by type and age. (DOCX $14 \mathrm{~kb}$ )

\section{Abbreviations}

AE: Adverse event; ANA: Antinuclear antibody; BIOBADASER: Spanish Registry for Adverse Events of Biological Therapy in Rheumatic Diseases; DMARD: Disease-modifying antirheumatic drug; FER: Spanish Society of Rheumatology; HLA: Human leukocyte antigen; IR: Incidence rate; JIA: Juvenile idiopathic arthritis; RA: Rheumatoid arthritis; RF: Rheumatoid factor; TB: Tuberculosis; TNFi: Tumor necrosis factor inhibitor

\section{Acknowledgements \\ The authors thank Jesús Sánchez-Costa and Cristina Oliva, clinical research associates, for their dedication to BIOBADASER.}

\section{Funding}

BIOBADASER is supported by the Research Unit of the Spanish Society of Rheumatology (FER) and the Spanish Agency for Medicines and Medical Devices (AEMyPS). Grants in approximately equal amounts were received from Biogen, Bristol-Myers Squibb, Pfizer, Roche, Samsung Bioepis, Lilly, Regeneron, Novartis, Janssen, Celgene, and MSD. These pharmaceutical companies had no role in this study. All researchers in this work are independent from the funders. In the collaboration contracts signed by the Spanish Society of Rheumatology, 
independence of the BIOBADASER registry has been affirmed with respect to the analyses as well as the diffusion of data and results.

\section{Availability of data and materials}

Please contact to the corresponding author for data requests.

\section{Authors' contributions}

JJBB and CSP wrote the initial draft of the manuscript. All authors had access to the data, contributed to its interpretation, and collaborated in the development of the manuscript. All authors critically reviewed and provided feedback on subsequent versions. All authors made the decision to submit the manuscript for publication and vouch for the accuracy and completeness of the data and fidelity of this report to the study protocol. All authors read and approved the final manuscript.

\section{Ethics approval and consent to participate}

The study was conducted in accordance with the principles of the Declaration of Helsinki. Ethics approval for the study was obtained from Hospital Clinic (Barcelona, Spain). The institutional review board at each participating center approved the protocol.

\section{Consent for publication}

Not applicable.

\section{Competing interests}

The authors declare that they have no competing interests.

\section{Publisher's Note}

Springer Nature remains neutral with regard to jurisdictional claims in published maps and institutional affiliations.

\section{Author details}

'Servicio de Reumatología, Hospital Universitario de Canarias, Tenerife, Spain. ${ }^{2}$ Research Unit, Sociedad Española de Reumatología, Madrid, Spain. ${ }^{3}$ Servicio de Reumatología, Hospital Universitario del Virgen Macarena, Sevilla, Spain. ${ }^{4}$ Servicio de Reumatología Hospital Universitario Miguel Servet, Zaragoza, Spain. ${ }^{5}$ Servicio de Reumatología, Hospital Universitario de Gran Canaria Dr. Negrín, Las Palmas, Spain. ${ }^{6}$ Servicio de Reumatología, Hospital Clínico Universitario de Santiago, A Coruña, Spain. ${ }^{7}$ Servicio de Reumatología, Hospital de La Princesa, Madrid, Spain. ${ }^{8}$ UGC de Reumatología, Instituto de Investigación Biomédica de Málaga (IBIMA), Hospital Regional Universitario de Málaga, Universidad de Málaga, Málaga, Spain. ${ }^{9}$ Servicio de Reumatología, Hospital San Jorge, Huesca, Spain. ${ }^{10}$ Servicio de Reumatología, Hospital Clinic de Barcelona, Barcelona, Spain. ${ }^{11}$ Servicio de Reumatología, Hospital General Universitario Valencia, Valencia, Spain. ${ }^{12}$ Servicio de Reumatología, Hospital Vall d'Hebron, Barcelona, Spain. ${ }^{13}$ Servicio Reumatología, Hospital Ramón y Cajal, Madrid, Spain. ${ }^{14}$ Servicio de Reumatología, Hospital 12 de Octubre, Madrid, Spain. ${ }^{15}$ Servicio de Reumatología, Hospital Universitario de Canarias, c/Ofra s/n 38320, La Laguna, Santa Cruz de Tenerife, Spain.

Received: 16 March 2018 Accepted: 19 September 2018

\section{Published online: 10 October 2018}

\section{References}

1. Petty RE, Southwood TR, Manners P, Baum J, Glass DN, Goldenberg J, He X, Maldonado-Cocco J, Orozco-Alcala J, Prieur AM, et al. International League of Associations for Rheumatology classification of juvenile idiopathic arthritis: second revision, Edmonton, 2001. J Rheumatol. 2004;31(2):390-2.

2. Thierry S, Fautrel B, Lemelle I, Guillemin F. Prevalence and incidence of juvenile idiopathic arthritis: a systematic review. Joint Bone Spine. 2014;81(2):112-7.

3. Martinez Mengual L, Fernandez Menendez JM, Solis Sanchez G, Fernandez Diaz M, Fernandez Gonzalez N, Malaga Guerrero S: Epidemiological study of juvenile idiopathic arthritis in the last sixteen years in Asturias (Spain) [in Spanish]. An Pediatr (Barc) 2007, 66(1):24-30.

4. Modesto C, Anton J, Rodriguez B, Bou R, Arnal C, Ros J, Tena X, Rodrigo C,

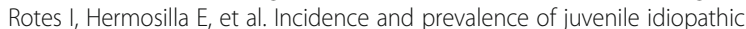
arthritis in Catalonia (Spain). Scand J Rheumatol. 2010;39(6):472-9.

5. Bowyer SL, Roettcher PA, Higgins GC, Adams B, Myers LK, Wallace C, Rennebohm R, Moore TL, Pepmueller PH, Spencer C, et al. Health status of patients with juvenile rheumatoid arthritis at 1 and 5 years after diagnosis. J Rheumatol. 2003;30(2):394-400.
6. Magni-Manzoni S, Rossi F, Pistorio A, Temporini F, Viola S, Beluffi G, Martin A, Ravelli A. Prognostic factors for radiographic progression, radiographic damage, and disability in juvenile idiopathic arthritis. Arthritis Rheum. 2003; 48(12):3509-17.

7. Mason T, Reed AM, Nelson AM, Thomas KB. Radiographic progression in children with polyarticular juvenile rheumatoid arthritis: a pilot study. Ann Rheum Dis. 2005;64(3):491-3.

8. Otten MH, Anink J, Prince FH, Twilt M, Vastert SJ, ten Cate R, Hoppenreijs EP, Armbrust W, Gorter SL, van Pelt PA, et al. Trends in prescription of biological agents and outcomes of juvenile idiopathic arthritis: results of the Dutch national Arthritis and Biologics in Children Register. Ann Rheum Dis. 2015;74(7):1379-86.

9. Stoll $\mathrm{ML}$, Cron RQ. Treatment of juvenile idiopathic arthritis: a revolution in care. Pediatr Rheumatol Online J. 2014;12:13

10. Shenoi S, Wallace CA. Tumor necrosis factor inhibitors in the management of juvenile idiopathic arthritis: an evidence-based review. Paediatr Drugs. 2010:12(6):367-77.

11. De Benedetti F, Brunner HI, Ruperto N, Kenwright A, Wright S, Calvo I, Cuttica R, Ravelli A, Schneider R, Woo P, et al. Randomized trial of tocilizumab in systemic juvenile idiopathic arthritis. N Engl J Med. 2012; 367(25):2385-95.

12. Lovell DJ, Ruperto N, Mouy R, Paz E, Rubio-Perez N, Silva CA, AbudMendoza C, Burgos-Vargas R, Gerloni V, Melo-Gomes JA, et al. Long-term safety, efficacy, and quality of life in patients with juvenile idiopathic arthritis treated with intravenous abatacept for up to seven years. Arthritis Rheumatol. 2015;67(10):2759-70.

13. Albers HM, Wessels JA, van der Straaten RJ, Brinkman DM, Suijlekom-Smit LW, Kamphuis SS, Girschick HJ, Wouters C, Schilham MW, le Cessie S, et al. Time to treatment as an important factor for the response to methotrexate in juvenile idiopathic arthritis. Arthritis Rheum. 2009:61(1):46-51.

14. Beukelman T, Patkar NM, Saag KG, Tolleson-Rinehart S, Cron RQ, DeWitt EM, llowite NT, Kimura Y, Laxer RM, Lovell DJ, et al. 2011 American College of Rheumatology recommendations for the treatment of juvenile idiopathic arthritis: initiation and safety monitoring of therapeutic agents for the treatment of arthritis and systemic features. Arthritis Care Res (Hoboken). 2011;63(4):465-82.

15. Otten $\mathrm{MH}$, Prince $\mathrm{FH}$, Armbrust $\mathrm{W}$, ten Cate $\mathrm{R}$, Hoppenreijs EP, Twilt $\mathrm{M}$, Koopman-Keemink Y, Gorter SL, Dolman KM, Swart JF, et al. Factors associated with treatment response to etanercept in juvenile idiopathic arthritis. JAMA. 2011;306(21):2340-7.

16. Wallace CA, Giannini EH, Spalding SJ, Hashkes PJ, O'Neil KM, Zeft AS, Szer IS, Ringold S, Brunner HI, Schanberg LE, et al. Trial of early aggressive therapy in polyarticular juvenile idiopathic arthritis. Arthritis Rheum. 2012;64(6):2012-21.

17. Guzman J, Oen K, Tucker LB, Huber AM, Shiff N, Boire G, Scuccimarri R, Berard R, Tse SM, Morishita K, et al. The outcomes of juvenile idiopathic arthritis in children managed with contemporary treatments: results from the ReACCh-Out cohort. Ann Rheum Dis. 2015;74(10):1854-60.

18. Selvaag AM, Aulie HA, Lilleby V, Flato B. Disease progression into adulthood and predictors of long-term active disease in juvenile idiopathic arthritis. Ann Rheum Dis. 2016;75(1):190-5.

19. Sharma N, O'Hare K, Antonelli RC, Sawicki GS. Transition care: future directions in education, health policy, and outcomes research. Acad Pediatr. 2014;14(2):120-7.

20. Luque Ramos A, Hoffmann F, Albrecht K, Klotsche J, Zink A, Minden K. Transition to adult rheumatology care is necessary to maintain DMARD therapy in young people with juvenile idiopathic arthritis. Semin Arthritis Rheum. 2017:47(2):269-75.

21. Castrejón I: Transitional care programs for patients with rheumatic diseases: review of the literature [in Spanish]. Reumatol Clin 2012, 8(1):20-26.

22. Calvo I, Anton J, Bustabad S, Camacho M, de Inocencio J, Gamir ML, Grana J, La Cruz L, Robledillo JC, Medrano M, et al. Consensus of the Spanish Society of Pediatric Rheumatology for transition management from pediatric to adult care in rheumatic patients with childhood onset. Rheumatol Int. 2015;35(10):1615-24.

23. Foster HE, Minden $\mathrm{K}$, Clemente $\mathrm{D}$, Leon L, McDonagh JE, Kamphuis $\mathrm{S}$, Berggren $K$, van Pelt P, Wouters C, Waite-Jones J, et al. EULAR/PReS standards and recommendations for the transitional care of young people with juvenile-onset rheumatic diseases. Ann Rheum Dis. 2017;76(4):639-46.

24. McErlane F, Foster HE, Davies R, Lunt M, Watson KD, Symmons DP, Hyrich $\mathrm{KL}$. Biologic treatment response among adults with juvenile idiopathic arthritis: results from the British Society for Rheumatology Biologics Register. Rheumatology (Oxford). 2013;52(10):1905-13.

25. Hilderson D, Eyckmans L, Van der Elst $K$, Westhovens R, Wouters C, Moons $P$. Transfer from paediatric rheumatology to the adult rheumatology setting: 
experiences and expectations of young adults with juvenile idiopathic arthritis. Clin Rheumatol. 2013;32(5):575-83.

26. Carmona L, de la Vega M, Ranza R, Casado G, Titton DC, Descalzo MÁ, Gómez-Reino J. BIOBADASER, BIOBADAMERICA, and BIOBADADERM: safety registers sharing commonalities across diseases and countries. Clin Exp Rheumatol. 2014:32(5 Suppl 85):S163-7.

27. Sanchez-Piedra C, Hernández Miguel MV, Manero J, Roselló R, SánchezCosta JT, Rodríguez-Lozano C, Campos C, Cuende E, Fernández-Lopez JC, Bustabad S, Martín Domenech R, Pérez-Pampín E, Del Pino-Montes J, MillanArciniegas AM, Díaz-González F, Gómez-Reino Jj; en representación del Grupo de trabajo BIOBADASER Fase III. Objectives and methodology of BIOBADASER phase iii. Reumatol Clin. 2017. https://doi.org/10.1016/j.reuma. 2017.08.001. [Epub ahead of print] English, Spanish.

28. Brown $E G$, Wood $L$, Wood $S$. The medical dictionary for regulatory activities (MedDRA). Drug Saf. 1999;20(2):109-17.

29. Lovell DJ, Ruperto N, Goodman S, Reiff A, Jung L, Jarosova K, Nemcova D, Mouy R, Sandborg C, Bohnsack J, et al. Adalimumab with or without methotrexate in juvenile rheumatoid arthritis. N Engl J Med. 2008;359(8):810-20.

30. Lovell DJ, Reiff A, llowite NT, Wallace CA, Chon Y, Lin SL, Baumgartner SW, Giannini EH. Safety and efficacy of up to eight years of continuous etanercept therapy in patients with juvenile rheumatoid arthritis. Arthritis Rheum. 2008:58(5):1496-504.

31. Ruperto N, Lovell DJ, Quartier P, Paz E, Rubio-Perez N, Silva CA, AbudMendoza C, Burgos-Vargas R, Gerloni V, Melo-Gomes JA, et al. Abatacept in children with juvenile idiopathic arthritis: a randomised, double-blind, placebo-controlled withdrawal trial. Lancet. 2008;372(9636):383-91.

32. Dimopoulou D, Trachana M, Pratsidou-Gertsi P, Sidiropoulos P, KanakoudiTsakalidou F, Dimitroulas T, Garyfallos A. Predictors and long-term outcome in Greek adults with juvenile idiopathic arthritis: a 17-year continuous follow-up study. Rheumatology. 2017;56(11):1928-38.

33. Harnett T. Who will treat arthritis in 2005? Rheumatologist. 2007;(1). https:// www.the-rheumatologist.org/article/who-will-treat-arthritis-in-2005/.

34. Foster HE, Marshall N, Myers A, Dunkley P, Griffiths ID. Outcome in adults with juvenile idiopathic arthritis: a quality of life study. Arthritis Rheum. 2003:48(3):767-75.

35. Minden K, Niewerth M, Listing J, Biedermann T, Bollow M, Schontube M Zink A. Long-term outcome in patients with juvenile idiopathic arthritis. Arthritis Rheum. 2002;46(9):2392-401.

36. Packham JC, Hall MA. Long-term follow-up of 246 adults with juvenile idiopathic arthritis: functional outcome. Rheumatology (Oxford). 2002;41 (12):1428-35.

37. Anink J, Prince FH, Dijkstra M, Otten MH, Twilt M, ten Cate R, Gorter SL, Koopman-Keemink Y, van Rossum MA, Hoppenreijs EP, et al. Long-term quality of life and functional outcome of patients with juvenile idiopathic arthritis in the biologic era: a longitudinal follow-up study in the Dutch Arthritis and Biologicals in Children Register. Rheumatology (Oxford). 2015; 54(11):1964-9.

38. Kearsley-Fleet L, McErlane F, Foster HE, Lunt M, Watson KD, Symmons DP, Hyrich KL. Effectiveness and safety of TNF inhibitors in adults with juvenile idiopathic arthritis. RMD Open. 2016;2(2):e000273.

39. Minden K, Niewerth M, Zink A, Seipelt E, Foeldvari I, Girschick H, Ganser G, Horneff $\mathrm{G}$. Long-term outcome of patients with JIA treated with etanercept results of the biologic register JuMBO. Rheumatology (Oxford). 2012;51(8): 1407-15.

40. Papsdorf $\mathrm{V}$, Horneff $\mathrm{G}$. Complete control of disease activity and remission induced by treatment with etanercept in juvenile idiopathic arthritis. Rheumatology (Oxford). 2011;50(1):214-21.

41. Mourão AF, Santos MJ, Melo Gomes JA, Martins FM, Mendonça SC, Oliveira Ramos F, Fernandes S, Salgado M, Guedes M, Carvalho S. Effectiveness and long-term retention of anti-tumour necrosis factor treatment in juvenile and adult patients with juvenile idiopathic arthritis: data from Reuma.pt. Rheumatology. 2015;55(4):697-703.

42. Favalli EG, Pontikaki I, Becciolini A, Biggioggero M, Ughi N, Romano M, Crotti C, Gattinara M, Gerloni V, Marchesoni A, et al. Real-life 10-year retention rate of firstline anti-TNF drugs for inflammatory arthritides in adult- and juvenile-onset populations: similarities and differences. Clin Rheumatol. 2017;36(8):1747-55.

43. Verazza S, Davi S, Consolaro A, Bovis F, Insalaco A, Magni-Manzoni S, Nicolai R, Marafon DP, De Benedetti F, Gerloni V, et al. Disease status, reasons for discontinuation and adverse events in 1038 Italian children with juvenile idiopathic arthritis treated with etanercept. Pediatr Rheumatol Online J. 2016;14(1):68.
44. Romano M, Pontikaki I, Gattinara M, Ardoino I, Donati C, Boracchi P, Meroni $\mathrm{PL}$, Gerloni V. Drug survival and reasons for discontinuation of the first course of biological therapy in 301 juvenile idiopathic arthritis patients. Reumatismo. 2014;65(6):278-85.

45. Pincus T, Stein CM. Why randomized controlled clinical trials do not depict accurately long-term outcomes in rheumatoid arthritis: some explanations and suggestions for future studies. Clin Exp Rheumatol. 1997;15(Suppl 17):S27-38.

\section{Ready to submit your research? Choose BMC and benefit from:}

- fast, convenient online submission

- thorough peer review by experienced researchers in your field

- rapid publication on acceptance

- support for research data, including large and complex data types

- gold Open Access which fosters wider collaboration and increased citations

- maximum visibility for your research: over $100 \mathrm{M}$ website views per year

At $\mathrm{BMC}$, research is always in progress.

Learn more biomedcentral.com/submissions 